\title{
SISTEMA DE MEDIÇÃO INDIVIDUALIZADA DE ÁGUA: ESTUDO DE CASO DE EDIFÍCIO COMERCIAL EM SÃO PAULO
}

\author{
Water supply individual measuring system: \\ case study of a commercial building in São Paulo - Brazil
}

Bárbara Cattapreta Lima', Juliana Keiko Yamaguchi², Lika Livia Kussaba ${ }^{3}$, Armando Traini Ferreira4

Recebido em 16 de fevereiro de 2015; recebido para revisão em 03 de junho de 2015; aceito em 18 de julho de 2015; disponível on-line em 11 de maio de 2016.

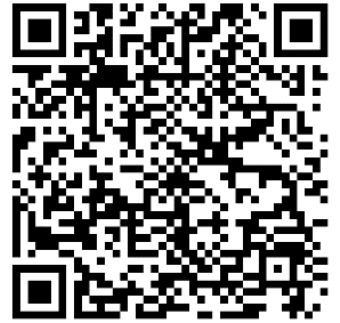

PALAVRAS CHAVE:

Medição individualizada;

Sustentabilidade de

edifícios;

Gestão da água;

Sistemas prediais.

KEYWORDS:

Individual water

metering;

Sustainability of buildings;

Water supply

management;

Buildings facilities

systems.

* Contato com os autores:

1 e-mail: bcattapreta@gmail.com

Téc., Ensino técnico de Edificações - Liceu de Artes e Ofícios de São Paulo - LAOSP

2 e-mail: julianakyamaguchi@gmail.com ( J. K. Yamaguchi)

Téc., Ensino técnico de Edificações - Liceu de Artes e Ofícios de São Paulo - LAOSP

${ }^{3}$ e-mail: Ikussaba@gmail.com

( L. L. Kussaba)

Téc., Ensino técnico de Edificações - Liceu de Artes e Ofícios de São Paulo - LAOSP

${ }^{4}$ e-mail: armandotraini@uol.com.br (A. T. Ferreira)

Prof., Ensino técnico de Edificações - Liceu de Artes e Ofícios de São Paulo - LAOSP

ISSN: 2179-0612 D.0.I. 10.5216/reec.V11i3.37331

C 2016 REEC - Todos os direitos reservados. 


\section{INTRODUÇÃO}

Com o aumento da demanda de água associado ao crescimento da população e ao desenvolvimento econômico, além de ações de desperdício, a disponibilidade de água no planeta vem ficando cada vez mais crítica. Segundo Oliveira (1999) existem diversas alternativas que auxiliam na redução e controle da água no meio urbano: (1) sistema de medição setorizada do consumo de água; (2) sistemas e componentes economizadores de água, (3) componentes de monitoramento e detecção e correção de vazamentos, entre outros. Assim, novos componentes tecnológicos vêm sendo instalados nas edificações visando o uso racional desse recurso natural e, entre eles, está à medição individualizada de água. Esse sistema é definido por Coelho (2004) da seguinte maneira:

"... consiste na instalação de hidrômetros no ramal de cada unidade habitacional, de modo que seja medido todo o seu consumo, com finalidade de racionalizar o uso da água e fazer a cobrança proporcional ao consumo individual".

Por muito tempo, a medição do consumo em sistemas de suprimento de água de condomínios vem sendo feita de forma coletiva. Assim, a divisão dos custos pelo consumo da água tem sido feita de modo que todos paguem a mesma quantia sobre o total consumido. Porém, o modo como se define os valores pagos pelo insumo vem sofrendo alterações com a implantação dos Sistemas de Medição Individualizada (SMI). Esta se destaca por considerar o consumo de cada apartamento separadamente, fazendo com que cada usuário pague o que realmente consumiu mais o gasto em áreas comuns do edifício, resultando em uma cobrança mais justa para os usuários. Assim, como as ações de consumo passam o influenciar diretamente sobre os gastos de cada um dos consumidores, estes passam a ter um incentivo ao uso mais consciente e racional da água potável.

Além disso, o SMI proporciona benefícios como a maior facilidade na detecção de vazamentos, que se dá por meio da percepção de alterações bruscas no perfil de consumo e, também, no valor cobrado após a sua instalação e estabilização da conta. O melhor controle de consumo também possibilita determinar separadamente o volume de efluente de esgoto sanitário gerado por cada unidade, permite maior capacidade de manobras de manutenção sem a necessidade de interrupção de grande parte do sistema de distribuição de água, induz a redução do consumo de energia e, também, a uma maior facilidade na identificação e controle de patologias pós-operação nos sistemas hidráulicos-sanitários prediais.

Em um primeiro momento, a instalação principalmente em edifícios já construídos pode parecer desvantajosa, devido ao custo de instalação das novas tubulações de distribuição de água e dos medidores, porém, na maioria dos casos, haverá retorno do investimento ao longo do tempo.

\section{OBJETIVOS}

Este artigo visa apresentar as principais vantagens e desvantagens da utilização de sistemas de medição Individualizada (SMI) de água em edifícios e, também, apresenta uma análise sobre o perfil e redução do consumo de água resultante da instalação de um SMI de água instalado em um prédio de tipologia comercial, situado em São Paulo - SP, possibilitando, assim, uma maior difusão dos SMI.

\section{SISTEMAS DE MEDIÇÃO DE ÁGUA}

O sistema de medição tradicional de água (sistema de medição coletiva de água) consiste na instalação de um hidrômetro geral na entrada da tubulação de suprimento de água da concessionária no edifício, o qual medirá o abastecimento que irá suprir todas as unidades de forma conjunta. Dessa maneira, a cobrança do consumo é dividida entre os apartamentos de forma igualitária, resultando em um recolhimento injusto de valores para as unidades que consomem menos água.

Neste caso, não é levada em consideração o número de agentes consumidores de cada unidade. Em edifícios onde há medição coletiva e, os gastos são incorporados à taxa de condomínio, 
o morador não fica ciente de seu consumo real e acaba não pagando diretamente por ele.

Em contraposição o SMI de água consiste na instalação de um medidor (hidrômetro) para cada apartamento de um condomínio ou unidade consumidora. De acordo com Yamada, Prado e loshimoto (2001), este sistema também leva em consideração fatores sociais, culturais e financeiros dos usuários, pois estas características estão diretamente conectadas aos comportamentos e procedimentos de utilização da água. Pesquisas feitas em Hong Kong por Chan (1997) mostram que o consumo per capta da população aumenta de acordo com o padrão de vida, dessa maneira, a oscilação do consumo se altera conforme a renda dos usuários.

Considerando os benefícios associados à implantação de SMI de água em edifícios, pode-se citar que os administradores de condomínios veem este sistema como uma ferramenta fundamental para uma gestão mais justa, pois além de induzirem a uma racionalização do consumo, também, resolvem parcialmente a inadimplência nas taxas de condomínio referentes à tarifa de água/esgoto.

Considerando os agentes consumidores o SMI favorece aos usuários que consomem menos água e, que pagam pelo uso alheio. Por sua vez, o SMI proporciona a cobrança adequada e compatível para os agentes que possuem hábitos esbanjadores de consumo de água, ação que motiva a um consumo mais racional e induz a redução do desperdício de água.

Do ponto de vista das concessionárias de abastecimento de água (empresas de saneamento) os SMI normalmente resultam na diminuição da inadimplência e, devido à redução de consumo, resulta na maior capacidade de suprimento do sistema de abastecimento de água, sem a necessidade de ampliação do mesmo.

Por outro lado, segundo Foletto (2008), uma das principais desvantagens do SMI, especialmente nos andares mais elevados de um edifício vertical, está relacionada à redução da pressão dinâmica na rede de distribuição de água. Uma vez que ocorre a concentração da distribuição de água em um número reduzido de prumadas e, também, é acrescido um medidor individual no ramal único de abastecimento de cada unidade de consumo. Esta configuração pode resultar em perdas de carga elevadas, que variam de acordo com a vazão de projeto de cada unidade, mas que podem resultar na necessidade de implementação de dispositivos pressurizadores para os últimos andares.

Os SMI de água, por normalmente resultarem em uma instalação com maior número de componentes, torna-se indispensável a manutenção preventiva e corretiva, principalmente quanto a calibração dos medidores.

As empresas concessionárias passam a se responsabilizarem por uma parte da instalação predial que antes era de responsabilidade dos condomínios e, também, precisam de ajustar os procedimentos de leitura dos medidores, devido ao aumento considerável do número de medidores a serem lidos. Este último pode ser resolvido com a implantação de sistemas de leitura remota.

Quanto a conservação dos hidrômetros, esta precisa ser feita exclusivamente por um técnico acreditado ou, por profissionais da própria concessionária. Assim sendo, consumidores, moradores e síndicos ficam impossibilitados de resolver qualquer problema, caso surja algum em um dos componentes situados em ramais de responsabilidade da concessionária. Logo, presume-se que tal serviço tenha um custo mais elevado que o convencional, podendo colocar em dúvida a viabilidade econômica desse sistema.

Em relação aos dados de consumo medido, pode haver reclamações à concessionária quando o somatório das medições individuais for menor que o volume total registrado no hidrômetro geral. Isto pode ocorrer devido a equipamentos descalibrados e, também, devido à defasagem entre as leituras dos diversos medidores. De acordo com a solução de medição adotada pela Concessionária, também pode-se ter maior dificuldade no controle e no impedimento de eventuais furtos de água e possíveis conflitos relacionados ao casual desrespeito à privacidade dos condôminos.

Além disso, segundo Mello (2010), quando se pretende instalar um sistema de medição 
individualizada de água em condomínios existentes, um dos grandes problemas enfrentados é a existência de válvulas de descargas nas bacias sanitárias. Mello (2010) cita que mesmo com a presença de válvulas modernas (válvulas com volume de descarga reduzido) no mercado brasileiro, a vazão instantânea deste componente é muito elevada em relação as demais vazões das unidades de consumo (torneiras de lavatórios, pias, tanques, duchas higiênica, chuveiros, etc.). Sendo assim, os medidores normalmente empregados para a medição individualizada não suportam faixas de leitura tão amplas e precisas, capazes de registrarem corretamente vazões elevadas e baixas em um mesmo ramal. Além da elevada vazão instantânea, necessária para o funcionamento das válvulas de descarga, a NBR 5626 (ABNT, 1998) também prevê colunas exclusivas (independentes dos demais pontos de consumo de água) para o seu abastecimento.

Segundo Bussolo (2010) uma solução para a adoção de SMI em edifícios com essa configuração, é substituir as bacias com válvula de descarga por bacias com caixa acoplada. Solução que pode ser realizada por meio de caixas que se adaptam às bacias com válvula de descarga, ou por meio da substituição da bacia existente, neste caso é necessária a realização de uma nova furação na laje e adaptação dos ramais de descarga.
Sendo assim, as principais vantagens e desvantagens do SMI podem ser resumidas conforme a Tabela 1.

Buscando viabilidade nos procedimentos de leitura dos medidores individuais de água, podese utilizar Sistema de Medição Individualizada com telemedição, ou medição remota, que, segundo Peres (2006), é uma tecnologia que vem sendo cada vez mais desenvolvida para auxiliar na leitura individual ou conjunta dos medidores eletrônicos (água, luz, gás, etc.). As tecnologias empregadas para este fim são diversas, dentre elas: centrais de coleta de dados com transmissão via radiofrequência, infravermelho, serviços gerais de pacote de rádio (GPRS), pela própria rede de energia elétrica (PLC), servidor de internet, entre outros.

Ademais, a medição remota possibilita a leitura de diversos medidores em um curto período de tempo, sem a necessidade de liberação de acesso de terceiros a áreas comuns dos edifícios e sem a necessidade de ampliação de mão de obra destinada a realização das atividades de leituristas.

O sistema de radiofrequência é bastante utilizado em construções já existentes, uma vez que utiliza menos eletrodutos, evitando novas instalações. Após a realização das medições, os dados de consumo coletados precisam ser levados para a central de medição, local onde estes serão

\begin{tabular}{|c|c|}
\hline VANTAGENS & DESVANTAGENS \\
\hline Justiça na cobrança de água & $\begin{array}{l}\text { Necessidade de mão de obra } \\
\text { especializada para a manutenção dos } \\
\text { cavaletes e medidores individuais }\end{array}$ \\
\hline $\begin{array}{l}\text { Melhor controle dos casos de } \\
\text { inadimplência e no corte de } \\
\text { fornecimento de água. }\end{array}$ & $\begin{array}{l}\text { Perda de carga excessiva no sistema } \\
\text { predial de distribuição de água }\end{array}$ \\
\hline Indução ao uso racional de água & $\begin{array}{c}\text { Inviabilidade técnica quanto ao uso de } \\
\text { válvulas de descarga em bacias } \\
\text { sanitárias }\end{array}$ \\
\hline $\begin{array}{l}\text { Maior facilidade na detecção de } \\
\text { anormalidades no perfil de } \\
\text { consumo, possibilitando ações de } \\
\text { manutenção mais rápidas e } \\
\text { eficientes. }\end{array}$ & $\begin{array}{l}\text { Necessidade de acesso de pessoal } \\
\text { terceirizado para a realização da } \\
\text { leitura dos medidores no caso de } \\
\text { sistemas convencionais de leitura }\end{array}$ \\
\hline
\end{tabular}


interpretados e a cobrança poderá, então, ser feita corretamente. A Figura 1 demonstra o caminho feito pelas informações de consumo considerando esta tipologia de SMI. De acordo com Tamaki (2003) a central de medição é responsável pelo recebimento, processamento, armazenamento e aplicação das informações obtidas pelos medidores, isto é, dos dados de consumos lidos nos hidrômetros dos condôminos. Utiliza-se um software para calcular estas informações e fornecer resultados digitais ou impressos que, por sua vez, são enviados para a concessionária para que a cobrança possa ser feita.

Já o sistema com geração de pulsos e transmissão via cabos permite maiores distâncias entre os medidores e as centrais de medição quando comparado com o sistema via radiofrequência. O sistema é bem vantajoso, uma vez que os custos são inversamente proporcionais à distância, ou seja, quanto mais distante o medidor da central, menor será o custo (GESTAG, 2009). O sistema via cabos é utilizado também quando não há dificuldade na passagem de eletrodutos, porém, deve-se estar atento para que não haja interrupção na transmissão de informações.

Independente do tipo de tecnologia empregada, com esse tipo de sistema de gestão de medição, os usuários podem ter fácil acesso aos dados de consumo, que são frequentemente atualizados, podendo inclusive serem gerados e disponibilizados em tempo real. Outra vantagem deste sistema de gestão de consumo associado ao SMI é a presença de equipamentos transdutores (transformam os valores de vazão em sinais elétricos) que servem para produzirem alertas sobre: a interrupção da alimentação, violação dos medidores, anormalidades no perfil de consumo com alerta de possíveis vazamentos, entre outras informações.

O tipo de medição remota a ser utilizado em cada edifício dependerá de cada projeto, e, também, dos padrões utilizados pela concessionária local, visando atender aos aspectos técnicos e de viabilidade financeira e, também, as necessidades dos usuários e do gestor de consumo, gerando normalmente resultados vantajosos para todas as partes envolvidas (NEJO, 2012).

A medição individualizada pode ser instalada tanto em prédios novos como em prédios antigos. Entretanto, é relativamente mais fácil e menos burocrática a execução desta em prédios novos, pois ela concebida na etapa de projeto e executada juntamente com a construção do edifício, enquanto que em prédios antigos ela é anexada a ele, gerando gastos para a adequação

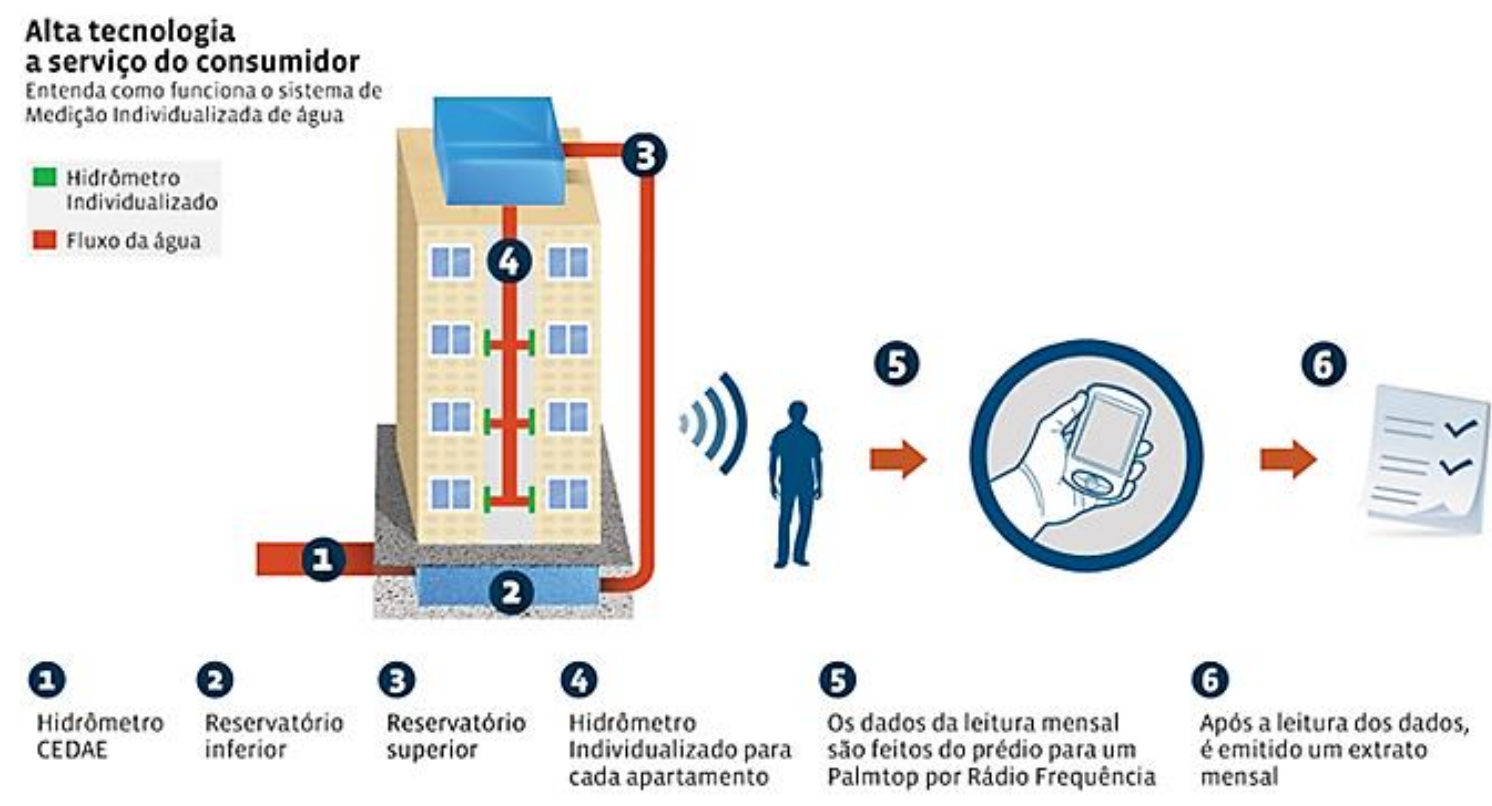

FIGURA 1: Esquema de SMI remoto por radiofrequência, no qual as informações são obtidas por hidrômetros, acessadas pelos leitores e enviadas aos palms para então ser emitido o extrato mensal.

FONTE: Hidroluz Engetema (2012). 
das instalações hidráulicas que serão feitas por meio de intervenções destrutivas e construtivas ao sistema já construído.

Segundo Coelho e Maynard (1999), seja em edifícios existentes ou não, a instalação de SMI de água deve seguir alguns critérios, estabelecidos pela NBR 5626 (ABNT, 1998), como: garantia de fornecimento contínuo de água, em quantidade suficiente, com pressão e velocidade adequadas, preservação da qualidade de água de abastecimento e a garantia de máximo conforto aos usuários, inclusive a diminuição do barulho.

Ainda de acordo com Coelho e Maynard (1999), o projeto de modificação de instalações prediais deve seguir algumas condições: (1) cada apartamento deverá ser abastecido por um único ramal de alimentação, no qual o hidrômetro individual será instalado (de preferência em local de fácil acesso para auxiliar na leitura), (2) é proibido a interligação entre as unidades do edifício; (3) as caixas de proteção (abrigo dos medidores) deverão seguir um padrão normalmente estabelecidos pela concessionária local, por fim, (4) não é permitida a utilização de válvulas de descargas, a não ser em casos específicos, em que a instalação contará com prumadas independentes e medidores que comportem a faixa de vazão destes componentes, realizando a medição de forma precisa.

Conforme os autores citados anteriormente, para o uso desse tipo de medição, no caso de um prédio novo, situado no estado de São Paulo, deve ser considerado no projeto o tipo de leitura e quem vai realizá-la, quem vai ser o responsável pelos medidores novos e pela emissão das contas de água e esgoto. Quando se trata de uma edificação existente, para a solicitação da medição individualizada, é preciso tomar algumas ações como:

- O síndico ou administradora do condomínio deve elaborar uma solicitação aprovada em conselho condominial e assinada pelos moradores, pedindo à concessionária um estudo de viabilidade para a implantação de SMI de água;
- O técnico da empresa concessionária de água inspeciona o local e fornece ao síndico as instruções e procedimentos para a implantação do SMI;

- O síndico contrata profissionais qualificados para o desenvolvimento do projeto e orçamentos das intervenções e reformas necessárias, seguindo da contratação de uma empresa especializada e com responsabilidade técnica para a sua execução;

- Após o sistema executado, a concessionária realiza uma inspeção local e autoriza ou não, a instalação dos hidrômetros individuais;

- É modificado o cadastro da unidade, associando as novas matrículas de cada apartamento com a matrícula do edifício.

\section{METODOLOGIA}

A metodologia utilizada para o desenvolvimento deste trabalho se baseia em um estudo de caso, para o qual foi selecionada uma edificação vertical para a comparação dos consumos registrados pós instalação do SMI de água e, também, para um melhor entendimento da operação e funcionamento do sistema de medição individualizada instalado nesta edificação.

O edifício estudado foi um prédio comercial de alto padrão, considerado o Triple $A$ da região, localizado na zona de Barueri, na região metropolitana da Grande São Paulo. O prédio possui 18 pavimentos de escritórios, e conta com lojas comerciais que integram o layout do térreo, além de uma estrutura completa de praça de alimentação e praça de serviços. O Edifício possui um acesso privado que o interliga a um grande Shopping Center, por meio de escadas rolantes.

O estudo de caso contou com a ajuda do engenheiro responsável pela obra, que forneceu os dados da edificação e, também, de aspectos da concepção, custos, métodos construtivos, materiais e outros, empregados no SMI implementado no edifício. Para o estudo foram registradas as informações de consumo de água, após a instalação do SMI em 4 (quatro) 
estabelecimentos comerciais do edifício. Porém, para maior detalhamento, foram comparados apenas os Estabelecimentos 1 e 4, os quais adotaram o SMI nos meses de Maio e Novembro, respectivamente.

Ambos os estabelecimentos são comércios alimentícios, porém o primeiro é uma unidade de uma rede de fast food e, portanto, apresenta maior número de usuários consumidores do que o quarto. As Figuras 3 e 4 mostram os medidores instalados nos estabelecimentos 1 e 4 respectivamente.

Para analisar a eficiência do sistema de medição individualizada de água implementado nas unidades avaliadas, foram monitorados dados de consumo em $\mathrm{m}^{3}$ e o valor pago pelo consumo registrado mensalmente. A observação e análise dos perfis de consumo de água mensal de cada estabelecimento foram utilizados para a definição de diferentes períodos que afetam os hábitos de consumo dos mesmos, após a instalação do SMI.

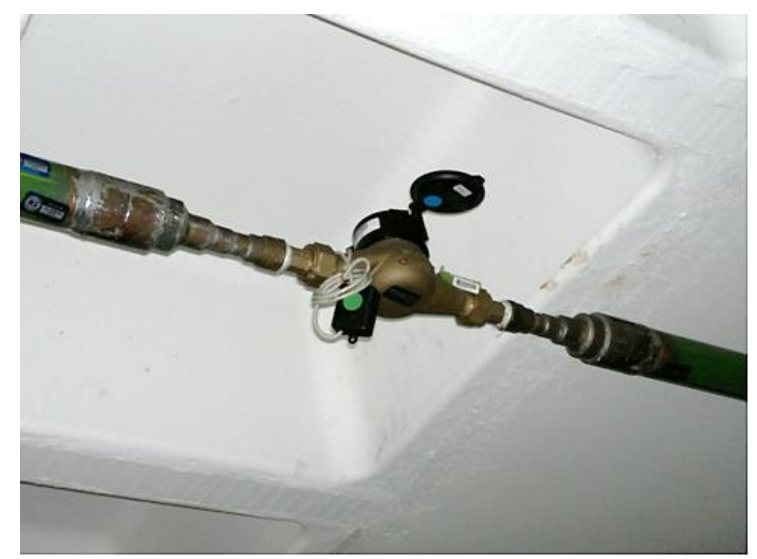

FIGURA 3: Hidrômetro instalado no Estabelecimento 1.

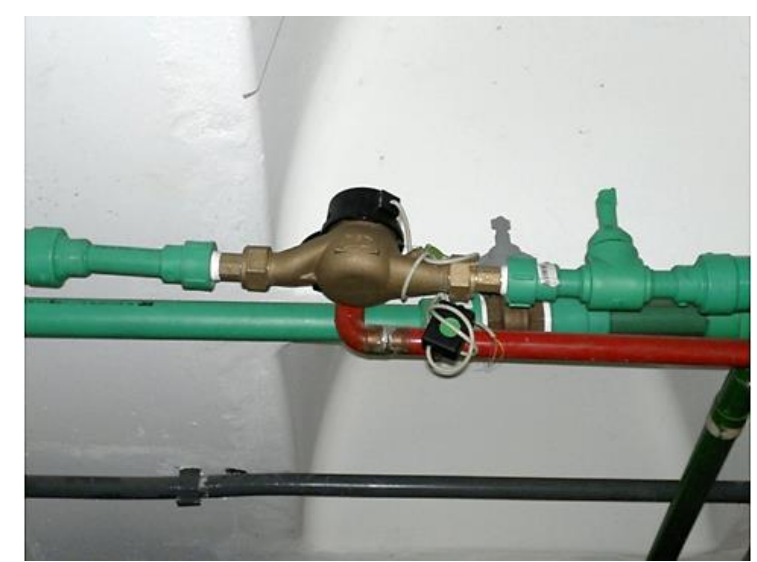

FIGURA 4: Hidrômetro instalado no Estabelecimento 4.
A comparação dos gastos pelo consumo de água imediatamente após a implantação do SMI, quando os hábitos de consumo ainda não haviam sido afetados pelo valor pago pela água e, após o período de estabilização de consumo, proporcionou a verificação se houve ou não adequações nos hábitos de consumo que resultassem no consumo mais racional de água pelos estabelecimentos.

\section{ESTUDO DE CASO}

A Tabela 2 refere-se aos dados de consumo e valores pagos para os períodos de estudo dos estabelecimentos 1 e 4.

Os custos apresentados na Tabela 2 são referentes à soma das tarifas de água e esgoto por metro cúbico de consumo, considerando seus custos equivalentes, na região metropolitana de São Paulo para unidades de tipologia comerciais. Considerou-se que as variações no preço do metro cúbico não influenciaram as comparações feitas neste estudo, já que elas afetam ambas as unidades igualmente. Com os dados das medições expostas, pode-se inicialmente identificar diferentes períodos definidos pelos perfis de consumo após a adesão ao SMI: (1) período inicial, caracterizado pelo desconhecimento do funcionamento do sistema; (2) período de adaptação, no qual acredita-se que pode gastar mais devido à diminuição dos custos pagos antes e depois da instalação; e (3) período de estabilização, durante o qual se observa a estabilização do valor pago e o retorno do investimento mais rapidamente devido à conscientização da utilização, restringindo-a ao necessário.

Para o Estabelecimento 1, o período definido como inicial corresponde aos três primeiros meses (de maio à julho), durante os quais houve grande oscilação dos valores pagos pelo consumo de água, entre $\mathrm{R} \$ 3.800,00$ e $\mathrm{R} \$ 5.500,00$ aproximadamente. Após o período inicial, observou-se o período de adaptação, que compreendeu os oito meses seguintes (de agosto a março), apresentando grandes variações dos 


\begin{tabular}{|c|c|c|c|c|c|c|c|c|}
\hline \multirow[b]{2}{*}{ Data } & \multirow[b]{2}{*}{$\mathrm{R} \$ / \mathrm{m}^{3}$} & \multicolumn{3}{|c|}{ ESTEBELECIMENTO 1} & \multirow{2}{*}{ Data } & \multicolumn{3}{|c|}{ ESTEBELECIMENTO 4} \\
\hline & & $\begin{array}{c}\text { Leitura } \\
\left(\mathrm{m}^{3}\right)\end{array}$ & $\begin{array}{c}\text { Consumo } \\
\left(\mathrm{m}^{3}\right)\end{array}$ & $\begin{array}{c}\text { Valor } \\
\text { (R\$) }\end{array}$ & & $\begin{array}{c}\text { Leitura } \\
\left(\mathrm{m}^{3}\right)\end{array}$ & $\begin{array}{c}\text { Consumo } \\
\left(\mathrm{m}^{3}\right)\end{array}$ & $\begin{array}{l}\text { Valor } \\
\text { (R\$) }\end{array}$ \\
\hline $27 / a b r$ & - & - & - & - & $27 / a b r$ & - & - & - \\
\hline $27 / \mathrm{mai} *$ & 14,807 & 307 & 307 & $4.545,75$ & $27 /$ mai & - & - & - \\
\hline 27/jun * & 14,807 & 568 & 261 & $3.864,63$ & $27 /$ jun & - & - & - \\
\hline $27 / \mathrm{jul} *$ & 14,807 & 945 & 377 & $5.582,24$ & 27/jul & - & - & - \\
\hline 26/ago ** & 14,807 & 1599 & 654 & $9.683,78$ & 26/ago & - & - & - \\
\hline $27 /$ set $* *$ & 14,807 & 2317 & 718 & $10,631,43$ & $27 /$ set & - & - & - \\
\hline $27 /$ out $* *$ & 15,46 & 2820 & 503 & $7.776,38$ & $27 /$ out & - & - & - \\
\hline $27 /$ Nov $* *$ & 15,46 & 2796 & -24 & $-371,04$ & $27 /$ Nov * & 28 & 28 & 432,88 \\
\hline $27 /$ dez $* *$ & 15,46 & 3180 & 384 & $5.936,64$ & $27 / \mathrm{dez} *$ & 290 & 262 & $4.050,52$ \\
\hline $24 /$ jan $* *$ & 15,46 & 3563 & 383 & $5.921,18$ & $24 /$ jan * & 434 & 144 & $2.226,24$ \\
\hline $24 / \mathrm{fev} * *$ & 14,824 & 4000 & 437 & $6.478,09$ & $24 / \mathrm{fev} * *$ & 632 & 198 & $2.935,15$ \\
\hline $24 / \operatorname{mar} * *$ & 14,824 & 4275 & 275 & $4.076,60$ & $24 / \operatorname{mar} * *$ & 758 & 126 & $1.867,82$ \\
\hline $27 / \mathrm{abr} * * *$ & 14,824 & 4464 & 189 & $2.801,74$ & $27 / a b r * *$ & 854 & 96 & $1.423,10$ \\
\hline $27 /$ mai $* * *$ & 14,824 & 4644 & 180 & $2.668,32$ & $27 /$ mai $* * *$ & 928 & 74 & $1.096,98$ \\
\hline 22/jun *** & 14,824 & 4814 & 170 & $2.520,08$ & $22 /$ jun $* * *$ & 1007 & 79 & $1.171,10$ \\
\hline $23 /$ jul $* * *$ & 14,824 & 4991 & 177 & $2.623,85$ & $23 /$ jul $* * *$ & 1084 & 77 & $1.141,45$ \\
\hline
\end{tabular}

valores pagos: de $\mathrm{R} \$ 4.000,00$ a $\mathrm{R} \$ 10.600,00$ aproximadamente. A oscilação observada neste período foi atribuída a percepção errônea, por parte da unidade consumidora, de que, a partir da instalação do SMI, o custo resultante apenas do consumo particular, resultaria em uma diminuição de gastos. Neste momento, também houve um consumo negativo, referente ao mês de novembro, o que pode significar um erro de medição ou um pagamento maior do que o devido no mês de outubro, havendo então um crédito de cerca de $\mathrm{R} \$ 370,00$ na conta de novembro. Por último, o período de estabilização, é composto pelos quatro meses seguintes (de abril a julho), durantes os quais os valores pagos tendem a fixar-se entre $\mathrm{R} \$ 2.500,00$ e $\mathrm{R} \$ 2.800,00$ aproximadamente.

Fazendo uma análise resumida, percebese que o valor pago pelo Estabelecimento 1 variou bastante durante $\mathrm{o}$ período de estudo. Inicialmente, o valor era considerado razoável para um edifício comercial e, em um dado momento, este valor subiu mais de $130 \%$ e posteriormente voltou a diminuir, estabilizando-se em torno de $\mathrm{R} \$ 2.500,00$ e passando a ser menor que os valores gastos no período inicial.

Para o Estabelecimento 4, o período inicial foi equivale aos três primeiros meses após a implantação do SMI (de novembro a janeiro), apresentando valores pagos variando entre $\mathrm{R} \$ 430,00$ e $\mathrm{R} \$ 4.000,00$ aproximadamente. Neste momento, pode-se observar que o mês de novembro apresentou baixo consumo, o que foi atribuído a uma previsão de consumo errada no primeiro mês de consumo após a instalação do SMI e ajustada com os valores cobrados no mês seguinte (dezembro). Assim, se considerar a média dos dois primeiros meses, o valor corresponderia a $\mathrm{R} \$ 2.241,70$, valor bastante próximo ao terceiro mês de consumo. Na sequência, considerou-se como período de adaptação os três meses seguintes (de fevereiro a abril), durante os quais os valores pagos oscilaram entre $\mathrm{R} \$ 1.400,00$ e $\mathrm{R} \$ 2.900,00$ aproximadamente. O período de estabilização foi composto pelos próximos três meses (de maio a 
julho), nos quais os valores tendem a fixar-se entre $\mathrm{R} \$ 1.090,00$ e $\mathrm{R} \$ 1.170,00$ aproximadamente.

Resumidamente, no Estabelecimento 4, o valor gasto devido ao consumo de água começa alto e em seguida tem um período de oscilação, apresentando um pico acentuado seguido de dois valores decrescentes, por fim o valor atinge um patamar de equilíbrio bem inferior aos valores gastos inicialmente.

Ainda analisando a Tabela 2, pode-se afirmar que ao se comparar os consumos mensais dos dois estabelecimentos, fica evidente que as fases de adaptação têm durações distintas entre os mesmos. O Estabelecimento 1 demorou aproximadamente oito meses para perceber que estava gastando além do que necessitava, enquanto o Estabelecimento 4 passou três meses gastando excessivamente. Nota-se então, que o Estabelecimento 1 passou mais tempo no período de adaptação após a implantação do SMI, comprovando o que o engenheiro responsável pela instalação do SMI havia afirmado, que em termos de ajustamento do perfil de consumo, cada caso deve ser tratado de forma particular.

Apesar disto, a observação dos três períodos (inicial, adaptação e estabilização) foi notada nos dois casos estudados. O estabelecimento de cada período depende muito das percepções, reações e adequações de cada um dos proprietários e usuários dos sistemas. Ainda assim, em ambos os casos a tendência de ajustamento é direcionada ao uso racional de água.
Tal resultado pode ser atribuído à maior facilidade de percepção do consumo de água associada ao valor pago pelo proprietário e, também, pela melhor utilização dos recursos por parte dos usuários, que readequaram seus hábitos, após notarem a possibilidade e/ou necessidade de reduzirem os gastos com o consumo de água.

Assim, ao final do período de adaptação, os dois estabelecimentos estudados atingiram um ponto de equilíbrio, onde o valor pago pelo consumo de água foi menor que os valores iniciais.

Por fim, a Tabela 3 apresenta uma comparação dos indicadores de consumo dos estabelecimentos estudados, que consiste na relação entre consumo e a área construída. Pode-se dizer que os valores observados são coerentes, como o Estabelecimento 1 é um comércio de maior porte e apresenta maior número de usuários / clientes, é esperado que seu consumo seja proporcional, ou seja, maior do que o consumo do Estabelecimento 4, que possui uma área menor e menos clientes.

É importante ressaltar que nas unidades do edifício que apresentarem um consumo inferior ao volume mínimo em relação à taxa de tarifação, o SMI possuirá somente a função de gerenciamento do consumo, lembrando que a cobrança pelo volume referente à taxa mínima depende de cada concessionária (ILHA, OLIVEIRA e GONÇALVES, 2010).

\begin{tabular}{|c|c|c|c|}
\hline \multicolumn{4}{|c|}{ TABELA 3: Comparação entre indicadores de consumo dos } \\
estabelecimentos $1 \mathrm{e} 4$. \\
\hline & $\begin{array}{c}\text { ÁREA } \\
\left(\mathbf{m}^{\mathbf{2}}\right)\end{array}$ & $\begin{array}{c}\text { CONSUMO } \\
\text { MENSAL MÉDIO } \\
\left(\mathrm{m}^{3}\right)\end{array}$ & $\begin{array}{c}\text { INDICADOR DE } \\
\text { CONSUMO } \\
\left(\mathrm{m}^{3} / \mathrm{m}^{2} / \mathrm{mês}\right)\end{array}$ \\
\hline ESTABELECIMENTO 1 & 508,36 & 332,8 & 0,65 \\
\hline ESTABELECIMENTO 4 & 306,72 & 120,4 & 0,39 \\
\hline
\end{tabular}




\section{CONSIDERAÇÕES FINAIS}

Considerando a água potável como um bem cada vez mais escasso, o conceito de sustentabilidade no ambiente construído ganha força, e os sistemas de medição individualizada de água sustenta os três quesitos deste conceito: econômico, social e ambiental.

Os sistemas de medição individualizada (SMI) podem ser concebidos com diferentes configurações, dependendo do que se pretende com o sistema. Portanto, pode-se inferir que fatores como tempo e dificuldade de implantação, além de período de retorno do investimento podem variar de acordo com cada situação.

Conforme observou-se por meio da avaliação bibliográfica, a medição individualizada de água quando implantada em edifícios, resultam em mais vantagens do que desvantagens. Do ponto de vista ambiental, podem ser citadas como vantagens, o desenvolvimento da consciência ambiental e a promoção do uso racional de água nos edifícios, além da maior facilidade da gestão de consumo e adoção de procedimentos economizadores de água. Do ponto de vista econômico pode-se citar a maior facilidade de gestão de consumo de água resultando em incentivos à redução de gastos com a tarifa de água, valorização do imóvel, redução do nível de inadimplência. Por fim, do ponto de vista social podem ser citados maior satisfação dos usuários e a promoção da justiça social devido a cobrança proporcional ao valor realmente consumido.

Por meio do estudo de caso observou-se que o SMI realmente resultou em uma redução no consumo de água de ambas as edificações estudadas. Observou-se também que, a implantação de um SMI em unidades já construídas e, em funcionamento, resulta em três diferentes períodos de percepção de consumo por parte dos usuários: período inicial, período de adaptação e período de estabilização de consumo. $O$ importante é ressaltar que em ambos os casos, o período de estabilização condiz com uma maior percepção e consciência de uso racional de água por parte dos usuários e proprietário dos estabelecimentos comerciais, o que gerou uma redução de consumo e de gastos com a tarifação de água.

A principal contribuição deste estudo consiste na ampliação do conhecimento sobre o funcionamento e operação dos sistemas de medição individualizada, mostrando que o sistema é eficiente na melhor gestão da água em edificações e, consequentemente pode ser considerado como agente incentivador do uso racional de água nas mesmas.

\section{AGRADECIMENTOS}

Agradecemos a Benito de La Fuente, engenheiro e Gerente de Infraestrutura da Jones Lang LaSalle, que forneceu os dados utilizados e esclareceu informações técnicas referentes ao estudo de caso.

\section{REFERÊNCIAS BIBLIOGRÁFICAS}

ASSOCIAÇÃO BRASILEIRA DE NORMAS TÉCNICAS. NBR 5626 - Instalação predial de água fria - Rio de Janeiro, 1998.

BUSSOLO, R. Comparativo executivo e econômico de medição coletiva e individual de água em edifícios residenciais multifamiliares. Trabalho de conclusão de curso - Universidade do Extremo Sul Catarinense, Criciúma, 2010.

CHAN, W. S. Demand management. Water Supply. V.15, n.1, p.35-39. 1997.

COELHO, A. C. Medição de água individualizada: manual do condomínio. Olinda: Luci Artes Gráficas, 2004.

COELHO, A. C. e MAYNARD, J. C. B.. Medição individualizada de água em apartamentos. Recife: Editora Comunicarte, 1999.

FOLETTO, T. B. Projeto de instalações hidráulicas com medição individualizada em edifícios residenciais. Trabalho de Conclusão de Curso - Universidade Federal de Santa Maria, Santa Maria, 2008.

Hidroluz Engetema. (2012). Medição individualizada de água. Disponível em: <www.hidroluz.com.br/ medicao_individualizada.aspx>. Acesso em 9 de novembro de 2014.

ILHA, M.; OLIVEIRA, L. H.; GONÇALVES, O. M. Sistemas de medição individualizada de água: como determinar as vazões de projeto para a especificação dos hidrômetros? Artigo Técnico - Engenharia Sanitária Ambiental, v.15, n.2, Abril/Junho 2010, p. 177-186. São Paulo. 2010. 
MELLO, E. J. (2010). O maior entrave para a medição individualizada da água. Disponível em: <www.medindoagua.com.br/2010/01/17/o-maiorentrave-para-amedicao-individualizada-da-agua/>.

Acesso em 12 de setembro 2014.

NEJO, M. B. P. Sistema de aquecimento solar com medição individualizada de água em edifícios residenciais. Monografia - Escola Politécnica da Universidade de São Paulo. São Paulo. 2012.

OLIVEIRA, L. H. Metodologia para a implantação de programa de uso racional da água em edifícios. Tese de doutorado - Escola Politécnica, Universidade de São Paulo, São Paulo, 1999.

PERES, A. R. B. Avaliação durante operação de sistemas de medição individualizada de água em edifícios residenciais. Dissertação - Universidade Federal de Goiás. Goiânia. 2006

TAMAKI, H. A medição setorizada como instrumento de gestão da demanda de água em sistemas prediais estudo de caso: programa de uso racional da água da Universidade de São Paulo. Dissertação - Escola Politécnica da Universidade de São Paulo. São Paulo. 2003.

YAMADA, E.; PRADO, R. e IOSHIMOTO, E. Os impactos do sistema individualizado de medição de água. Boletim técnico - Escola Politécnica da Usp. São Paulo. 2001. 